\title{
Situs Inversus Totalis: A Clinical Review
}

\author{
Katalin Eitler $\mathbb{D}^{\prime}$, András Bibok $\mathbb{D}^{2}$, Gábor Telkes $\mathbb{D}^{1}$ \\ 'Department of Surgery, Transplantation and Gastroenterology, Semmelweis University, Budapest, Hungary; ${ }^{2}$ Medical Imaging Centre, Semmelweis \\ University, Budapest, Hungary \\ Correspondence: Gábor Telkes, Department of Surgery, Transplantation and Gastroenterology, Semmelweis University, VIII. Baross u.23., Budapest, \\ $\mathrm{H}$-1082, Hungary, Tel +36 20825 8593, Email telkesdr@gmail.com
}

\begin{abstract}
Situs inversus totalis is a rare congenital abnormality characterized by a mirror-image transposition of both the abdominal and the thoracic organs. While this anomaly is known since the ancient times, practicing doctors do not have much experience with it. Laterality is established early in development, and any failure in that process might lead to a wide variety of disorders which may be partial or complete. Situs solitus describes the normal anatomy, situs inversus is the complete reversal, and situs ambiguous is used for any other abnormality of left-right development. Sidedness is regulated by genes: over 100 genes have been linked to laterality defects. Frequency of situs inversus is 1:10,000 and is more frequent in males: 1.5:1. Advanced imaging modalities can be used to assess fine anatomical details, which play a crucial role in these cases to plan radiologic or surgical interventions. Percutaneous biliary procedures, portal vein embolization are really challenging procedures in SIT patients due to the mirror effect. As most surgeons are right-handed, SIT operations can cause difficulties: handling the instruments with their left hand or the pedals with their left foot can be uncomfortable Organ, especially liver transplantation represents an extraordinary surgical challenge. Solutions to overcome the anatomic differences include the use of segment or reduced size graft with rotation, modified piggy-back technique, side to-side caval anastomosis, and vascular conduit. Because of its rarity and special nature, surgical patients with situs inversus may require more flexibility and creativity from the surgical team.
\end{abstract}

Keywords: situs inversus totalis, left-right asymmetry, mirror-image transposition, kidney transplantation, liver transplantation, organ donation

\section{Plain Language Summary}

Nearly all visceral organs of the thorax and abdomen are left-right asymmetrical in their anatomy and placement. Situs inversus is the mirror-image transposition of the organs. This is a rare condition, affecting 1:10,000 people. Laterality is established early in foetal development and over 100 genes have been linked to laterality defects. Any failure in the normal left-right asymmetry stands in a spectrum of disturbances. Because of its rarity, practising doctors usually do not have much experience with these patients. Advanced imaging modalities like computer tomography (CT) or magnetic resonance imaging (MRI) can be used to assess fine anatomical details. The diagnosis of situs inversus is especially important in emergency situations. Clinically, situs inversus by itself is asymptomatic. A thorough assessment of the patient's anatomy is recommended before Surgery. These patients require more flexibility and creativity from the surgical team; however, many cases that have been reported were treated successfully.

\section{Introduction}

Situs inversus totalis (SIT) is a rare congenital abnormality characterized by a mirror-image transposition of both the abdominal and the thoracic organs (Figure 1). This is a global defect of situs orientation, as the failure to generate normal left-right asymmetry results in a spectrum of laterality disturbances. ${ }^{1}$ This condition might cause difficulties during diagnostic and therapeutic procedures. Because of its rarity, practising doctors, eg, gastroenterologists, radiologists, and surgeons usually do not have much experience with these patients. Even a busy surgeon may expect to encounter this anomaly only once or twice in a lifetime. ${ }^{2}$

In this review, we focus on the surgical and clinical importance of situs inversus totalis. 


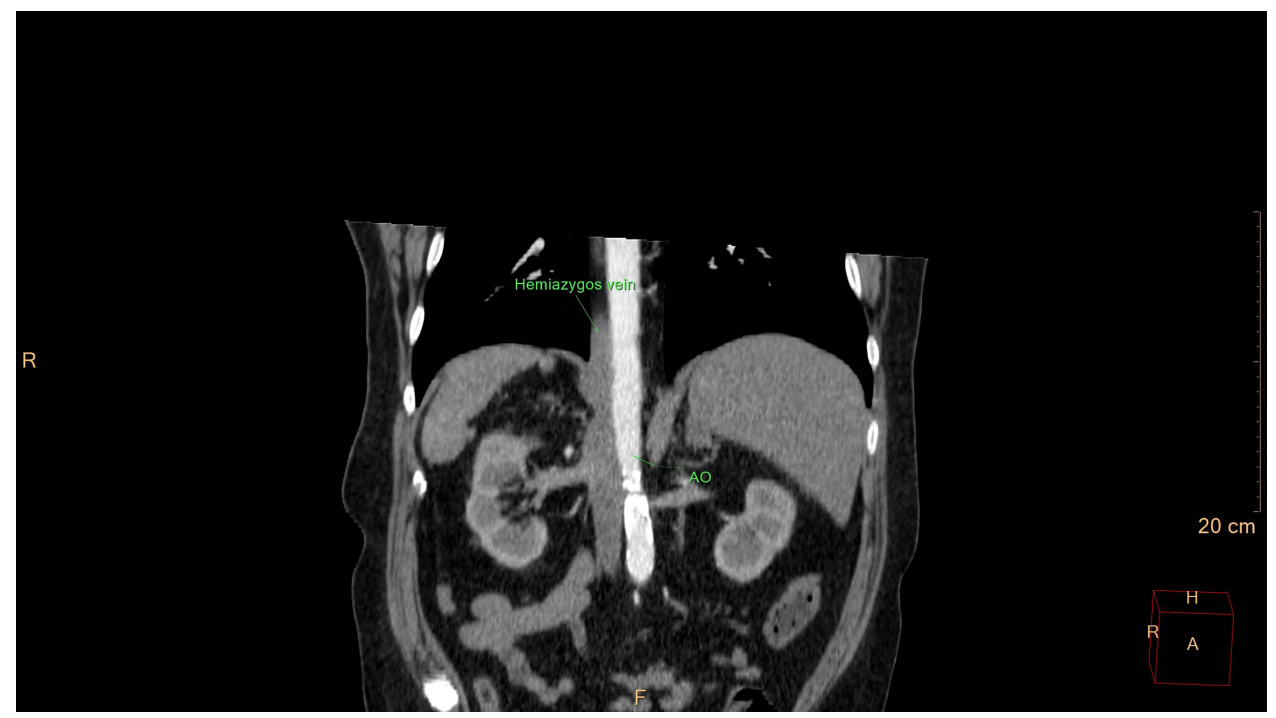

Figure I Characteristic CT-scan in SIT: coronal reconstruction of contrast-enhanced CT.

\section{History}

This anomaly was first described in animals by Aristotle (BC. 384-322). ${ }^{3}$ We had to wait to the first observations in humans till the 17th century. Fabricius reported the first known case of reversal of the liver and spleen in man in $1600 .{ }^{4}$ A few years later, in 1652, Riolan, dean of the medical faculty of the University of Paris, reported two cases. ${ }^{5}$ Marco Severino first recognized dextrocardia in 1643 (https://emedicine.medscape.com/article/413679-overview).

Küchenmeister was the first who observed four cases in living persons by physical examination and reported this with drawings in 1888. He called this anatomical situation "situs viscerum transversus". ${ }^{6}$ To Vehsemeyer is given the credit for being first to demonstrate the transposition of the viscera in 1897 by X-ray. ${ }^{7}$ Since then, imaging has been the method of choice to clarify the anatomy.

\section{Terminology}

The body of vertebrate species shows an external bilateral symmetry. Therefore, it is surprising that humans and all other vertebrates present an internal asymmetry: nearly all visceral organs are left-right (LR) asymmetrical in their anatomy and placement. The normal disposition of organs is called situs solitus. ${ }^{1}$ Any failure in the normal left-right asymmetry stands within a spectrum of laterality disturbances. Heterotaxia (from Greek: "heteros" and "taxis") is the common term used for these disorders. It encompasses a wide variety of disorders which may be partial or complete. The asymmetry of unpaired organs (heart, liver, spleen, stomach, bowels, aorta, v. cava) seems to be logic and "unavoidable". The asymmetry of paired organs seems less obvious, but they have distinct left and right forms. The lungs have major differences (three lobes vs two lobes), but even kidneys show some asymmetry. Especially the vascular differences between left and right kidneys have some technical importance, eg, for transplant surgeons.

The terminology, as described in the literature, is a bit confusing. The complete reversal of normal organ position, including both the thoracic and abdominal organs, is called situs inversus totalis. Between the two "extremities", situs solitus (normal) and situs inversus (reversed) totalis, lies the spectrum of situs ambiguous (indeterminate), which, according to Aylsworth, is characterized by isomerism, heterotaxy, and multiple malformations in one or more thoracic or abdominal organs. ${ }^{8}$ However, Kosaki et al use the term situs ambiguous when the entire anatomic left-right axis is neither normal nor mirror-image reversed. ${ }^{9}$ Peeters et al use this term for the failure of asymmetry of unpaired organs (a condition where at least one organ shows a reversed orientation), in some contrast with isomerism, which refers to a defect in asymmetry of paired organs. Moreover, these conditions are frequently associated with each other. ${ }^{1}$ Probably, it is wise to follow Kosaki's advice and use situs solitus for normal anatomy, situs inversus for complete reversal, and situs ambiguous for any other abnormality of LR development. 
It must always be kept in mind that malrotation, a congenital anomaly of the intestinal position, is different from situs inversus. The liver, bile ducts and the gallbladder, the oesophagus, the stomach, the duodenum and the pancreas develop from the foregut; these do not rotate during embryonic development. Intestines (the small intestine and the colon until the transverse colon) develop from the midgut and they rotate $270^{\circ}$ counterclockwise around the superior mesenteric artery. Malrotation results from an error of this process. Thus, malrotation is independent of situs inversus. ${ }^{10,11}$

\section{Embryology, Genetics}

In a population-based Baltimore-Washington Infant Study using multivariate analyses of cases and controls, six risk factors for SIT were identified: family history of heart defects, family history of noncardiac anomalies, maternal diabetes, antitussive use, paternal smoking, and low socioeconomic status. ${ }^{12}$ These factors might have some connection with genetic mutations, as major advances in the identification of gene mutations in animals and humans support a growing body of knowledge about the causes of laterality defects. ${ }^{13}$

It is reasonable to assume that monozygotic twins are more likely to show evidences of SIT. However, that is not the case. Situs inversus is seldom seen in identical twins. ${ }^{2,14}$ In a multicenter study analysing 1812 individuals, Baneke et al were unable to calculate meaningful heritability for SIT, due to insufficient numbers. ${ }^{15}$ The situation may differ for conjoined twins. The incidence of situs inversus in them is far too high to be due to chance alone. ${ }^{16}$

Laterality is established early in development and is orchestrated by a cascade of signal molecules and genes. Importantly, the neurotransmitter serotonin (5HT) also plays a critical role in this signalling cascade that establishes laterality. ${ }^{10}$ Sidedness is established at the time of primitive streak formation (gastrulation) and is regulated by genes, such as Nodal and PITX2, which become restricted in their expression. Partial reversal of left-right asymmetry is more often associated with other defects than complete asymmetry (situs inversus). ${ }^{10}$ The discovery of these cascades has also shed light on the cause of situs defects in conjoined twins. ${ }^{17}$

Genetic deletions of KIF3-A or KIF3-B, two microtubule-dependent kinesin motor proteins, resulted in a randomization of the situs of the viscera. In case of non-functional KIF3, the cell-adhesion factors N-cadherin and $\beta$ catenin are not transported to the cell surface. These proteins are involved in the development and progression of cancer. ${ }^{18-20}$ Reversed cerebral asymmetry is associated with breast cancer, suggesting that some aspects of laterality mechanisms also participate in growth and pattern control processes. ${ }^{21}$ Most cases of heterotaxy are sporadic occurrences without a recognizable cause. ${ }^{12}$

Understanding how directional information is converted into global position will be a key piece of the puzzle. Over 100 genes have been linked to laterality defects, including primary ciliary dyskinesia (PCD) genes, which has led to a greater focus on the overlap between PCD and the full spectrum of laterality defects between situs solitus and situs inversus totalis.

\section{Epidemiology}

It is difficult to provide a valid estimation of real frequency. There are only a few own observations in the literature and a lot of citations.

The incidence of all lateralization defects is approximately $1: 15,000$ according to the Orphanet. ${ }^{22}$ Heterotaxy is present in approximately 1 in 10,000 births. ${ }^{23}$ The incidence of situs inversus itself is reported to be 1:6500 to 1:25,000, see Table 1.

We performed a search in our radiologic database, looking for situs inversus as key words in the results. Between 2006 and 2020, 217,646 imaging examinations (ultrasound, CT and plain radiography) were performed at the Department

Table I Estimated Frequency of LR Disorders

\begin{tabular}{|l|l|l|l|l|}
\hline Heterotaxy & $\mathrm{I}: 10000^{23}$ & & & \\
\hline Situs ambiguous & $\mathrm{I}: 10000^{13}$ & $\mathrm{I}: 15000^{22}$ & & \\
\hline Situs inversus totalis & $\mathrm{I}: 20000^{24}$ & $\mathrm{I}: 6-8000^{1}$ & $\mathrm{I}: 6500^{2}$ & $\mathrm{I}: 25000^{25}$ \\
\hline
\end{tabular}


of Transplantation and Surgery, Semmelweis University. Out of them, 21 cases were found, which represents a 1:10,000 frequency. This hospital-based prevalence rate best reflects Adams et al in 1937 (23:232,113), and Lin et al in 2000 (20:201,084) from Massachusetts, as data from own observations. ${ }^{26}$ This rate is similar as well to the population-based Baltimore-Washington Infant Study. ${ }^{12}$ SIT is slightly more frequent in males: 1.5:1. ${ }^{27}$

\section{Syndromic LR Defects}

Sometimes LR malformations arise as only one manifestation of a broader spectrum of so-called syndromic LR defects. The most common of these is the immotile cilia syndrome, whose name was changed to "primary ciliary dyskinesia" (PCD) as it describes more appropriately its heterogeneous genetic base and the ciliary dysfunction. ${ }^{28}$ The first cases, reported in the early 1900's, became known as the Kartagener syndrome, the triad of situs inversus, bronchiectasis and sinusitis. ${ }^{28-30}$ Affected individuals suffer from chronic respiratory tract infections and from a variable combination of infertility in males, chronic ear infections and decreased or absent sense of smell. These problems arise because of defective cilia and flagella (sperm tails have a similar structure). ${ }^{9}$

Several other syndromes associated with abnormal situs have been described as well, including polysplenia syndrome, asplenia or Ivemark's syndrome. ${ }^{31}$ Ivemark and asplenia/polysplenia syndromes do not constitute distinct etiological entities and therefore these terms should be avoided. ${ }^{1}$

Situs ambiguous is very frequently associated with cardiac malformation: $80 \%$ of these patients present complex congenital heart disease, detected basically in childhood. The rate of congenital heart disease is around $0.6 \%$ in situs solitus (normal anatomy), 3-9\% in situs inversus totalis, and almost $80 \%$ in situs ambiguous. This highlights the importance of relative organ position with respect to each other for proper morphogenesis. ${ }^{1,32}$ Vascular anomalies such as an interrupted inferior vena cava (INT-IVC) and preduodenal portal vein (PDPV) have been reported in as many as $20 \%$ and $42 \%$ of situs anomaly patients, respectively. ${ }^{33}$ Aberrant hepatic arterial anatomy also has a higher frequency in patients with abnormal situs. Biliary atresia (BA) is commonly found in patients with abnormal situs. $^{34-36}$

\section{Medical Imaging}

Although situs inversus can be suspected following a careful physical examination, the wide availability of medical imaging and routine screening programs make it possible to confirm the findings and look for further details and pathologies. Traditional imaging modalities like ultrasound (US) or plain film X-ray are usually the first choice of diagnostic imaging. Typical findings are dextrocardia, left-placed liver and right-placed spleen - rarely even with polysplenia. ${ }^{37-40}$ Advanced imaging modalities like computer tomography (CT) or magnetic resonance imaging (MRI) can be used to assess fine anatomical details and possible pathological findings (Figure 1). Prenatal MRI of the foetus can even provide a detailed description of situs anomalies well before delivery. ${ }^{41}$ Nuclear medicine imaging is also feasible in situs inversus, but technical details need to be considered, like detector position during cardiac SPECT imaging. ${ }^{42}$ If available, fusion with CT or MRI can help to understand the anatomy that may not be visible on functional imaging. SPECT/CT with ${ }^{99 m}$ Tc-labeled native red blood cells can be useful to differentiate between polysplenia and abdominal masses. ${ }^{43-45}$

Congenital cardiovascular disorders are found frequently in situs inversus, highlighting the role of advanced thoracic and abdominal imaging with CT and/or MRI. ${ }^{46-49}$

Caval vein disorders are also common. The most common variation is left-sided inferior caval vein (IVC). In some cases, the distal part of the VCI is absent or interrupted. ${ }^{47,50}$ These malformations may come with higher risks of deep vein thrombosis. The superior vena cava can be on the left side as well. ${ }^{48}$

The diagnosis of situs inversus is especially important in emergency scenarios. Olasehinde et al reported a case of a polytraumatized patient with an accidental finding of situs inversus totalis during exploratory laparotomy. ${ }^{51}$ Similarly, acute abdominal diseases, like cholecystitis, acute appendicitis or splenic injury will present with uncommonly located symptoms. ${ }^{52-55}$ Typically, diagnosing these acute abdominal diseases is part of the daily routine; however, medical imaging can help clarify the diagnosis when symptoms are atypical due to situs anomalies. Patients with situs inversus 
may develop malignant or benign neoplasms just like patients without situs anomalies. ${ }^{56-62}$ Medical imaging plays a crucial role in these cases to properly plan possible surgical treatment.

\section{Interventional Radiology (IR)}

There are only a few cases reported in the literature when a patient with situs inversus underwent an interventional radiological procedure. ${ }^{63-67}$ Gasparrini et al reported a patient with situs inversus totalis who underwent repeated TACE treatments after Fontan surgery. ${ }^{68}$ Variant origin of the hepatic artery (from the superior mesenteric artery) further complicated the case.

Percutaneous biliary procedures are far more challenging, as the operator needs to work on the "wrong" side. Routine procedures like patient lying, placement of angio team members and C-arm location may also need to be revised when working with a situs inversus patient. Our work group's recent paper presents a patient with a biliary stricture who underwent multiple biliary procedures. ${ }^{69}$ Compared to traditional percutaneous biliary drainage procedures in our institute, we placed the patient heading the opposite direction in order to stay on the usual side to work. The operator and the IR nurse changed their position and the ceiling-hanged monitor was moved behind the IR nurse to allow a clear view. All IR procedures were uneventful and complication-free. Giordano et al and Gupta et al described a very similar workflow for PTD in situs inversus totalis patients. ${ }^{63,65}$

Similarly to PTD, portal vein embolization (PVE) can also be challenging due to the mirror-effect. So far there is only one reported case of PVE on a situs inversus totalis patient published by Faria et al. ${ }^{66}$

Balloon-occluded retrograde transvenous obliteration (BRTO) is a minimally invasive treatment for patients with gastric varices. ${ }^{70}$ Watanabe et al reported a single case of a situs inversus patient who underwent BRTO. ${ }^{67}$

\section{Endoscopy Gastro- and Colonoscopy}

To perform an oesophago-gastro-duodenoscopy (EGD) in situs inversus a "mirror-technic" is required which means that the insertion tube together with the left-right and up-down wheels move inversely as within a normal procedure. ${ }^{71}$ A clearer endoscopic view can be obtained placing the patient in right lateral position and the endoscopist on the opposite side, with rearranging the endoscopic room. ${ }^{72}$

In the literature, several reports of successful endoscopic interventions can be found.

These include endoscopic submucosal dissection of early gastric cancer, ${ }^{72}$ PEG (percutaneous endoscopic gastrostomy) insertion using a pre-existing abdominal surgical incision in an obese patient, ${ }^{73}$ endoscopic papillectomy, ${ }^{74}$ endoscopic myotomy. ${ }^{75}$

Choi et al reported 5 colonoscopies made by situs inversus patients between 2001 and 2006. The cecal intubation time was prolonged, but a complete colonoscopy was possible. ${ }^{76}$

\section{ERCP}

The most challenging procedure in situs inversus is the endoscopic retrograde cholangiopancreatography (ERCP). Despite the difficulty, many publications can be found about successful interventions, like sphincterotomy, stone extraction, biliary dilatations and placing biliary stents. Most of the procedures were performed with the patient in ventral position, with the duodenoscope rotated through $180^{\circ}$ in the second part of the duodenum to enable visualization of the ampulla.

Endoscopic procedures can be combined in altered anatomy, too. In a 65-year-old man, a conventional ERCP revealed 2 giant intraductal stones, lithotripsy could not be performed. Intraductal cholangioscopy and laser lithotripsy were successful. ${ }^{77}$ One interesting case was published about double-balloon enteroscopy-assisted ERCP procedure in a patient who had undergone earlier Roux-en-Y hepatico-jejunostomy following iatrogenic bile duct injury during cholecystectomy. Dilatation of the anastomotic stenosis and placing a plastic biliary tube was performed by keeping the patient in a standard ERCP position. ${ }^{78}$ 
Post-surgical interventions together with congenital anatomic alterations can complicate the endoscopic methods. Kim et al reported the first case of ERCP in situs inversus totalis following a Billroth II. gastrectomy. Neither the patient's nor the endoscopist's position was changed. The major papilla was accessed with a forward-viewing endoscope. ${ }^{79}$ Billroth I. anatomy enables the use of a side-viewing duodenoscope inserted along the lesser curve of the stomach into the duodenum, rotated counterclockwise, placed the patient in the prone position with the endoscopist on his right side. ${ }^{80}$

There are only a few reports about endoscopic ultrasound (EUS) for diagnostic or therapeutic procedures. Kumbhari et al reported the first EUS in a patient with situs inversus totalis, and revealed a pancreatic malignancy. The position of the patient (left to right lateral) and the echoendoscope (linear to radial) was changed during the procedure, too. ${ }^{81}$ Cecinato et al performed a successful EUS-guided transgastric biliary drainage because of a solid mass of pancreatic isthmus involving the entire common bile duct, duodenum, portal vein and mesenteric axis, causing duodenal stenosis. ${ }^{82}$ Cases of extrahepatic cholangiocarcinomas proved with EUS followed by ERCP were published, too..$^{25,83}$

\section{Surgery}

\section{General Surgery}

A thorough assessment of the patient's anatomy is recommended before surgery. Of note to the general surgeon, abnormal sidedness of cardiac structures is frequently associated with abnormal relationships of the thoracic and abdominal organs.

Clinically, SIT by itself is asymptomatic; however, when it is associated with other conditions, the diagnosis may represent a challenge due to the reversed anatomical location of symptoms. This clinical presentation can be explained by the fact that the organs are transposed, but the peripheral nervous system components are not, allowing the patient to experience diffuse abdominal pain. ${ }^{84}$

In laparoscopic procedures, careful consideration of trocar positioning is necessary. ${ }^{85}$ There are no standard port positions in these situations and the surgeon has to modify the port placements adhering to the basic principles of laparoscopy - triangulation and ergonomy. The main advantage of laparoscopic procedures is that they can be tailored to every patient with minimal modification of the standard procedure - placement of the trocars is widely variable. ${ }^{86,87}$ On the other hand, as a result of these modifications, incisions in inappropriate sites have been documented in more than $40 \%$ of such cases. ${ }^{84}$

Handedness of the lead surgeon in these cases may influence the outcome of the surgery, because most of the human population is right-handed. Surgical procedures are designed for right-handed surgeons but can be approached by the lefthanded in alternative ways. ${ }^{88}$ The connection between handedness and professions was explored in many studies and found most of the surgeons right-handed. ${ }^{89}$ The left-handed part of the population could have the gift of high aptitude for visuospatial skills, which could be very useful practicing surgery, as well.

However, for right-handed surgeons, it can cause some difficulties: handling the instruments with their left hand or the pedals with their left foot can be uncomfortable. ${ }^{90}$ Very tiring situations can occur: using the right hand has technical difficulties of either having to cross the hands or hyperflex the trunk, and these could have an effect on the surgical outcome, too. ${ }^{91}$

\section{LC}

There are several reports in the literature about laparoscopic cholecystectomy (LC) in SIT. The most widely used technique described is by placing an umbilical trocar for the camera and three trocars in the standard subcostal positions mirrored to the left. The surgeon and the assistant stand on the right, while the monitor is situated on the left side of the patient. In this situation, the surgeon can hold the infundibulum (Hartmann's pouch) with the left hand through the subxiphoid port and can use the right hand to perform the dissection through the left midclavicular port. ${ }^{52}$ This kind of "American mirror technique" was used by most surgeons according to a recent review. ${ }^{92}$ This is ergonomically a bit 
inconvenient as the surgeon has to lean across the patient's body. The operation time is reported to be longer than the average in normal anatomy. ${ }^{93-96}$

In our unit, we do not use a second assistant for standard LC: the camera assistant grasps and retracts the fundus. The colleague who performed a laparoscopic cholecystectomy in a SIT patient described the whole situation as "difficult" (personal communication, case not published).

\section{Appendectomy}

Appendicitis in unusual locations or situations always poses a diagnostic dilemma. Abdominal CT is widely accepted and used in acute abdominal diseases, therefore in rare and/or puzzling situations it belongs to the essential diagnostic options. ${ }^{97,98}$ In the case of SIT, the laparoscopic procedure has even more advantages compared to normal anatomy. The operation can be carried out laparoscopically if possible; if not, an appropriate surgical incision can be made. ${ }^{99}$ The camera can be introduced through the umbilical port, the other port positions can be then placed according to the exact position of the appendix and the technique is to be modified to suit each individual patient. ${ }^{74}$

\section{Other Operations}

Many other surgical procedures have been reported in SIT patients. These include sleeve gastrectomy for morbid obesity, ${ }^{100,101}$ proximal gastric resection, ${ }^{102}$ "distal" gastric resection, ${ }^{103,104}$ total gastrectomy for malignancy, ${ }^{105,106}$ laparoscopic pancreato-duodenectomy, ${ }^{107}$ nephrectomy, ${ }^{108}$ complicated choledochal cyst ${ }^{109}$ and different colorectal operations, eg, sigmoid resection, rectal resection, etc. ${ }^{110,111}$

We previously published a case of malignant masquerade biliary stricture in a situs inversus totalis patient (who gave his written consent to that) when distal resection of the common bile duct, cholecystectomy and hilar lymphadenectomy were performed. $^{69}$

After encountering the initial disorientation, experienced surgeons can perform these procedures successfully and safely.

\section{Transplantation}

Organ transplantation might pose extremely challenging surgery in the case of SIT. Theoretically, both the donor and the recipient can have situs inversus, but taking account of the rarity, it is very unlikely to find such matching donor-recipient pairs. In our unit, which is a high-volume kidney and liver transplant center within the Eurotransplant, so far we have not met a donor with situs inversus and we did not perform transplantation in SIT recipient.

\section{Kidney}

As kidneys are paired and more or less symmetric organs, situs inversus should not cause serious difficulties. There are several reports about living donations and performing laparoscopic nephrectomies, with excellent result, as it was expected. ${ }^{112-115}$ Detailed imaging is mandatory to reveal the exact anatomy.

Reports about recipients having SIT are even more sparse. Ochi et al reported three cases, and concluded that kidney transplantation is the same, except that attention should be paid to venous anastomosis. ${ }^{116}$ With multidisciplinary efforts and thorough surgical preparation at a high-volume transplant centre, this procedure is feasible and safe. ${ }^{117}$

\section{Liver}

The liver is an asymmetric organ and is always involved in anatomic disturbances related to SIT. Therefore, both the donation from a SIT donor and the transplantation into a SIT recipient represent extraordinary surgical challenges. Situs inversus was once regarded as a contraindication to liver transplantation because of the technical difficulties associated with the unique vascular anatomy and concern about achieving accurate graft positioning. ${ }^{118}$ The first liver transplantation in a SIT recipient was published in $1988 .{ }^{119}$ Watson et al in 1995 reported 8 cases. ${ }^{120}$ They selected relatively small donor organs or reduced-size grafts and used a modification of the "piggy-back" technique of suprahepatic vena caval anastomosis to overcome the recipient's venous anomalies. The modified piggy-back technique is advocated by others, as well. ${ }^{121,122}$ Solutions to overcome anatomic differences include side to-side caval anastomosis, reduced and rotated graft 
(90 degrees clockwise), for which relatively smaller grafts are to be preferred. ${ }^{123,124}$ This technique is most suited for this anatomical variation in the opinion of Sankarankutty. ${ }^{125}$ The rotation $\left(15-90^{\circ}\right)$ and the use of reduced size grafts seems to be an accepted solution for that rare situation. ${ }^{126-128}$

In the case of living donation, the use of segmental liver transplantation gives more freedom for the transplant surgeon to figure out the best option. If there is enough time for preoperative planning, the new techniques, such as 3D printing, can help procedure planning. ${ }^{129}$ Pomposelli and Rayhill used a 180-degree ventral caudal (backward) rotation. $^{130,131}$

Plication of the left diaphragm together with stabilization of the graft, use of vascular conduits or splenectomy to make space should be considered as well. However, thrombotic complications, including even the need of retransplantations, are more frequent than in a normal setting. ${ }^{109}$

Although different successful approaches have been proposed, agreement on a standard technique has not been achieved. Careful perioperative planning, thorough anatomic knowledge of both the donor and the recipient liver, flexibility and creativity for use of a variety of different novel techniques can lead to beneficial outcomes.

\section{Conclusion}

The establishment of left-right asymmetry is a fascinating problem in embryonic morphogenesis. ${ }^{132}$ Given that complete situs inversus presents no medical disadvantage, why do not individuals with situs solitus co-exist in roughly equal numbers with those with situs inversus? ${ }^{133}$ Significant progress in our understanding of the molecular genetic basis of right-left patterning has recently been made, but the crucial details of the origin of asymmetry remain unknown.

Medical imaging is capable of visualizing the fine details of situs anomalies and is essential before any further invasive therapy.

All IR procedures can be performed on patients with situs inversus totalis; however, some may need technical modifications because of the "mirror effect". Diagnostic and interventional endoscopy means a difficulty in this anatomical rarity, but all the known procedures could be achieved by experts using a mirror-technic, with or without changing the position of the patient and endoscopists, or type of the endoscope.

This uncommon malformation has been challenging and amazing for many surgeons. Because of its rarity and special nature, surgical patients with situs inversus may require more flexibility and creativity from the surgical team; however, many cases that have been reported in the literature could have been treated successfully.

\section{Abbreviations}

BA, biliary atresia; BRTO, balloon-occluded retrograde transvenous obliteration; CT, computed tomography; EGD, oesophago-gastro-duodenoscopy; ERCP, endoscopic retrograde cholangiopancreatography; EUS, endoscopic ultrasound; INT-IVC, interrupted inferior vena cava; IR, interventional radiology; IVC, inferior caval vein; LC, laparoscopic cholecystectomy; LR, left-right; MRI, magnetic resonance imaging; PCD, primary ciliary dyskinesia; PDPV, preduodenal portal vein; PEG, percutaneous endoscopic gastrostomy; PTD, percutaneous transhepatic drainage; PVE, portal vein embolization; SIT, situs inversus totalis; SPECT, single photon emission computed tomography; TACE, transarterial chemoembolization; US, ultrasound.

\section{Informed Consent}

Our patient with biliary stricture in situs inversus totalis gave his written informed consent for publication.

\section{Acknowledgments}

We say a very special thanks to Dr. Veronika Papp, consultant gastroenterologist, who has written the section "Endoscopy".

\section{Authors' Information}

K Eitler: surgical fellow. 
A Bíbok: specialist of radiology.

G Telkes PhD.: consultant general and transplant surgeon.

\section{Funding}

The authors did not receive any funding.

\section{Disclosure}

The authors declare no conflicts of interest for this work.

\section{References}

1. Peeters H, Devriendt K. Human laterality disorders. Eur J Med Genet. 2006;49(5):349-362. doi:10.1016/j.ejmg.2005.12.003

2. Blegen HM. Surgery in situs inversus. Ann Surg. 1949;129(2):244-259. doi:10.1097/00000658-194902000-00009

3. Aristotle's Generation of Animals. In: Falcon A, Lefebvre D (editors). Aristotle's Generation of Animals: A Critical Guide (Cambridge Critical Guides, p. I). Cambridge: Cambridge University Press; 2018. ISBN-13:978-1107132931

4. Fabricius CO, Blalock A. Situs inversus totalis and disease of biliary tract; survey of literature and report of case. Arch Surg. 1940;40:885-896. doi:10.1001/archsurg. 1940.04080040067007

5. Moore GA. Situs inversus abdominalis complicated by ileo-caecal tuberculosis producing acute intestinal obstruction. Ann Surg. 1925;81 (2):511-517. doi:10.1097/00000658-192502010-00010

6. Küchenmeister F. Die angeborne, vollständige seitliche Verlagerung der Eingeweide des Menschen (situs viscerum totalis lateralis rarior, solito inversus) [The congenital, complete lateral displacement of the human viscera]. Zwiete Ausgabe, Leipzig, Verlag von T Stauffer; 1888. German.

7. Vehsemeyer A. Ein fall von congenitaler Detiokardie: zugleich ein Beitrag zur Verwerthung der Röntgenstrahlen in Gebiete der inner Medizin [A case of congenital dextrocardia and a contribution to the utilization of X-rays in areas of internal medicine]. Deutsche Medizinische Wochenschrift. 1897;23(12):180-181. German.

8. Aylsworth AS. Clinical aspects of defects in the determination of laterality. Am J Med Genet. 2001;101(4):345-355. doi:10.1002/ajmg.1219

9. Kosaki K, Casey B. Genetics of human left-right axis malformations. Semin Cell Dev Biol. 1998;9(1):89-99. doi:10.1006/scdb.1997.0187

10. Sadler TW. Langman's medical embryology. In: Yamada T, editor. Textbook of Gastroenterology. 14th ed. Vol. 2. Philadelphia: JB Lippincott; 1995.

11. Adams SD, Stanton MP. Malrotation and intestinal atresias. Early Hum Dev. 2014;90(12):921-925. doi:10.1016/j.earlhumdev.2014.09.017

12. Ferencz C, Loffredo CA, Correa-Villasenor A, Wilson PD. Defects of laterality and looping. In: Genetic and Environmental Risk Factors of Major Cardiovascular Malformations. The Baltimore-Washington Infant Study: 1981-1989. Armonk: Futura Publishing Company. Inc; 1997:41-58.

13. Lin AE, Ticho BS, Houde K, Westgate MN, Holmes LB. Heterotaxy: associated conditions and hospital-based prevalence in newborns. Genet Med. 2000;2(3):157-172. doi:10.1097/00125817-200005000-00002

14. Segal NL. Situs inversus totalis in twins: a brief review and a life history/twin research: twin studies of trisomy 21 ; monozygotic twin concordance for bilateral coronoid hyperplasia; prenatal hormonal effects in mixed-sex non-human primate litters; insurance mandates and twinning after in vitro fertilization/news reports: first report of identical twin puppies; twins sisters turn 100; remembering an identical twin production designer; New York City Marathon Quadruplets. Twin Res Hum Genet. 2017;20(1):90-95. doi:10.1017/thg.2016.101

15. Baneke AJ, Williams KM, Mahroo OA, Mohamed M, Hammond CJ. A twin study of cilioretinal arteries, tilted discs and situs inversus. Graefes Arch Clin Exp Ophthalmol. 2018;256(2):333-340. doi:10.1007/s00417-017-3859-7

16. Layton WM. Situs inversus in conjoined twins. Am J Med Genet. 1989;34(2):297. doi:10.1002/ajmg.1320340236

17. Levin M, Roberts DJ, Holmes LB, Tabin C. Laterality defects in conjoined twins. Nature. 1996;384(6607):321. doi:10.1038/384321a0

18. Haruki T, Maeta Y, Nakamura S, et al. Advanced cancer with situs inversus totalis associated with KIF3. Complex deficiency: report of two case. Surg Today. 2010;40:162-166. doi:10.1007/s00595-009-4005-x

19. Teng J, Rai T, Tanaka Y, et al. The KIF3 motor transports N-cadherin and organizes the developing neuroepithelium. Nat Cell Biol. 2005;7:474-482. doi:10.1038/ncb1249

20. Sulik K, Dehart DB, Iangaki T, et al. Morphogenesis of the murine node and notochordal plate. Dev Dyn. 1994;201(3):260-278. doi:10.1002/ aja.1002010309

21. Sandson TA, Wen PY, LeMay M. Reversed cerebral asymmetry in women with breast cancer. Lancet. 1992;339(8792):523-524. doi:10.1016/ 0140-6736(92)90341-y

22. Orphanet. The portal for rare diseases and orphan drugs. Available from: https://www.orpha.net/consor/cgi-bin/Disease_Search.php?lng= EN\&data_id=8556\&MISSING\%20CONTENT=Heterotaxia\&search=Disease_Search_Simple\&title=Heterotaxia\#. Accessed February 125, 2022.

23. Grimes DT, Burdine RD. Left-right patterning: breaking symmetry to asymmetric morphogenesis. Trends Genet. 2017;33(9):616-628. doi:10.1016/j.tig.2017.06.004

24. Burn J. Disturbance of morphological laterality in humans. Ciba Found Symp. 1991;162:282-299. doi:10.1002/9780470514160.ch16

25. Coronel M, Lanke G, Cambell D, et al. Performing endoscopic retrograde cholangiopancreatography and endoscopic ultrasound for management of malignant bile duct obstruction in a patient with a situs inversus totalis. ACG Case Rep J. 2020;7(12):e00483. doi:10.14309/ crj.0000000000000483

26. Adams R, Churchill ED. Situs inversus, sinusitis, bronchiectasis; five cases, including frequency statistics. J Thoracic Surg. 1937;7:206-217. doi:10.1016/S0096-5588(20)32282-0

27. Lee SE, Kim HY, Jung SE, Lee SC, Park KW, Kim WK. Situs anomalies and gastrointestinal abnormalities. J Pediatr Surg. 2006;41 (7):1237-1242. doi:10.1016/j.jpedsurg.2006.03.045 
28. Leigh MW, Pittman JE, Carson JL, et al. Clinical and genetic aspects of primary ciliary dyskinesia/Kartagener syndrome. Genet Med. 2009;11 (7):473-487. doi:10.1097/GIM.0b013e3181a53562

29. Kartagener M. Zur pathogenese der bronkiectasien: bronkiectasien bei situs viscerum inversus [On the pathogenesis of bronchiectasia: bronhiectasia in situs inversus]. Beitr Klin Tuberk. 1933;82:489-501. German. doi:10.1007/BF02141468

30. Padilla JA, Xuriguera E, Rodríguez L, et al. Chapter 2 - development of the lungs; perinatal and developmental lung disease. In: Corrin B, Nicholson AG, editors. Pathology of the Lungs. Third ed. Churchill Livingstone; 2011:39-90. doi:10.1016/B978-0-7020-3369-8.00002-1

31. Ivemark BI. Implications of agenesis of the spleen on the pathogenesis of conotruncus anomalies in childhood; an analysis of the heart malformations in the splenic agenesis syndrome, with fourteen new cases. Acta Paediatr Suppl. 1955;44(Suppl 104):7-110. doi:10.1111/j.16512227.1955.tb05346.x

32. Merklin RJ, Varano NR. Situs inversus and cardiac defects. A study of 111 cases of reversed asymmetry. J Thorac Cardiovasc Surg. 1963;45:334-342. doi:10.1016/S0022-5223(19)32866-1

33. Loukas M, Strike DR, Tubbs RS, Tarneja N, Shoja MM. An interrupted inferior vena cava in a situs inversus. Case report and review of the literature. Folia Morphol (Warsz). 2009;68(3):184-187.

34. Fulcher AS, Turner MA. Abdominal manifestations of situs anomalies in adults. Radiographics. 2002;22(6):1439-1456. doi:10.1148/ rg. 226025016

35. Applegate KE, Goske MJ, Pierce G, Murphy D. Situs revisited: imaging of the heterotaxy syndrome. Radiographics. 1999;19(4):837-854. doi:10.1148/radiographics.19.4.g99j131837

36. Ruben GD, Templeton JM, Ziegler MM. Situs inversus: the complex inducing neonatal intestinal obstruction. J Pediatr Surg. 1983;18 (6):751-756. doi:10.1016/s0022-3468(83)80018-9

37. Haththotuwa HR, Dubrey SW. A heart on the right can be more complex than it first appears. BMJ Case Rep. 2013;2013:bcr2013201046. doi:10.1136/bcr-2013-201046

38. Paschala A, Koufakis T. Looking in the mirror: situs inversus totalis. Pan Afr Med J. 2015;20:87. doi:10.11604/pamj.2015.20.87.6139]

39. Kwon SH, Shin SY. Incidental adult polysplenia with situs inversus, interrupted inferior vena cava with azygos continuation, patent ductus arteriosus, and aortic branches variations: a case report. J Thorac Dis. 2018;10(2):E138-E141. doi:10.21037/jtd.2018.01.1284

40. Suthar T, Banker H, Shah M, Thakkar G. Splenic infarct with polysplenia syndrome and situs inversus. BMJ Case Rep. 2012;2012: bcr0220125831. doi:10.1136/bcr.02.2012.5831

41. Nemec SF, Brugger PC, Nemec U, et al. Situs anomalies on prenatal MRI. Eur J Radiol. 2012;81(4):e495-501. doi:10.1016/j.ejrad.2011.06.016

42. Pawar SU, Shetye SS, Ghorpade MK, Azeez Seena R. Assessment of myocardial viability using nuclear medicine imaging in dextrocardia. J Nucl Med Technol. 2020;48(4):372-377. doi:10.2967/jnmt.120.248435

43. Wang P, Jing H, Li F, Wang Z, Huo L. 99mTc-labeled native RBC scintigraphy in distinguishing polysplenia from abdominal masses in a patient with situs inversus totalis. Clin Nucl Med. 2019;44(12):998-1000. doi:10.1097/RLU.0000000000002825

44. Brown KM, Gundara JS, Mittal A. Acute gastrointestinal manifestation of situs inversus abdominus. Hernia. 2017;21(4):649-651. doi:10.1007/ s10029-016-1519-1

45. Schmutzer KJ, Linde LM. Situs inversus totalis associated with complex cardiovascular anomalies. Am Heart J. 1958;56(5):761-768. doi:10.1016/0002-8703(58)90218-7

46. Sohns JM, Steinmetz M, Schneider H, et al. Situs inversus totalis with congenitally corrected transposition of the great arteries: insights from cardiac MRI. Springerplus. 2014;3:601. doi:10.1186/2193-1801-3-601

47. Del Prete A, Cavaliere C, Di Pietto F, De Ritis R. Situs inversus with levocardia, infrahepatic interruption of the inferior vena cava, and azygos continuation: a case report. Surg Radiol Anat. 2016;38(3):369-371. doi:10.1007/s00276-015-1454-3

48. Batouty NM, Sobh DM, Gadelhak B, Sobh HM, Mahmoud W, Tawfik AM. Left superior vena cava: cross-sectional imaging overview. Radiol Med. 2020;125(3):237-246. doi:10.1007/s11547-019-01114-9

49. Wolla CD, Hlavacek AM, Schoepf UJ, Bucher AM, Chowdhury S. Cardiovascular manifestations of heterotaxy and related situs abnormalities assessed with CT angiography. J Cardiovasc Comput Tomogr. 2013;7(6):408-416. doi:10.1016/j.jcct.2013.11.008

50. Oliveira N, Oliveira F, Dias E, Borges L, Cássio I. Leriche syndrome in a patient with situs inversus totalis. Ann Vasc Surg. 2015;29(6):1317. e5-8. doi:10.1016/j.avsg.2015.02.023

51. Olasehinde O, Owojuyigbe AM, Adisa AO, Awowole IO. Incidental finding of complete situs inversus in a polytraumatized adult. Afr J Med Med Sci. 2014;43(2):183-186.

52. Herrera Ortiz AF, Lacouture JC, Sandoval Medina D, Gómez Meléndez LJ, Uscategui R. Acute cholecystitis in a patient with situs inversus totalis: an unexpected finding. Cureus. 2021;13(6):e15799. doi:10.7759/cureus.15799

53. Di Buono G, Maienza E, Buscemi S, Randisi B, Romano G, Agrusa A. Acute appendicitis in a patient with situs viscerum inversus totalis: role of laparoscopic approach. A case report and brief literature review. Int J Surg Case Rep. 2020;77S:S29-S33. doi:10.1016/j.ijscr.2020.10.047

54. Versluis J, Suliman HM. Appendicitis in a patient with situs inversus totalis. JBR-BTR. 2014;97(3):182-183. doi:10.5334/jbr-btr.77

55. Kamath B, Chatterjee AS, Chandorkar I. Splenic injury in situs inversus totalis - a surgical challenge. J Clin Diagn Res. 2015;9(5):PD01-02. doi:10.7860/JCDR/2015/13376.5871

56. Cao Y, Li J, Shen L, et al. Gastric cancer in a situs inversus totalis patient with multiple intestinal and vessel variations related to gastrectomy surgery: a case report and literature review. Medicine (Baltimore). 2017;96(39):e8209. doi:10.1097/MD.0000000000008209

57. Calabria FF, Leporace M, Bagnato A. Situs inversus totalis and cholangiocarcinoma of the gallbladder detected by 18 F-FDG PET/CT. Clin Nucl Med. 2018;43(6):439-440. doi:10.1097/RLU.0000000000002047

58. Abbey E, Yang F, Qi L, Wu JJ, Tong L, Zhen Z. Situs inversus totalis patients with gastric cancer: robotic surgery the standard of treatment?-A case report. Int J Surg Case Rep. 2021;81:105818. doi:10.1016/j.ijscr.2021.105818

59. Xiang D, He J, Fan Z, et al. Situs inversus totalis with solid pseudopapillary pancreatic tumor: a case report and review of literature. Medicine (Baltimore). 2018;97(12):e0205. doi:10.1097/MD.0000000000010205

60. Chen L-J, Qiu X, Sun H, Xu P-F, Yin F-M, Xu L-J. Two types of lung cancer with situs inversus totalis: a case report and review of the literature. J Int Med Res. 2020;48(9):300060520944107. doi:10.1177/0300060520944107

61. Wang -T-T, Xia Q-H, Yu X, Chen X-D. The first report of renal oncocytoma in a patient with situs inversus totalis. Asian J Surg. 2020;43 (4):571-572. doi:10.1016/j.asjsur.2019.12.005 
62. Vishwanath Reddych V, Prakash A. Solid pseudopapillary neoplasm of pancreas in a patient of situs inversus totalis. BMJ Case Rep. 2019;12 (8):e231644. doi:10.1136/bcr-2019-231644

63. Gupta N, Goyal P, Bansal I, Li S, Kumar Y, Baijal SS. Modified palliative biliary stenting in situs inversus totalis patient with carcinoma gallbladder: feasibility and technical details. Transl Gastroenterol Hepatol. 2017;2:27. doi:10.21037/tgh.2017.03.01

64. Miraglia R, Maruzzelli L, Mamone G, Luca A. Percutaneous recanalization of a segmental inferior vena cava occlusion in a patient with situs viscerum inversus and symptomatic Budd-Chiari syndrome. Dig Liver Dis. 2019;51(6):909. doi:10.1016/j.dld.2019.02.007

65. Giordano G, Bonomo S, Failla G, Luigiano C, Caloggero S, Magnano San Lio V. Percutaneous transhepatic biliary drainage after failed endoscopic approach in patients with pancreatic cancer and situs inversus totalis. Endoscopy. 2014;46(Suppl 1 UCTN):E628-629. doi:10.1055/ s-0034-1390779

66. Faria I, Souza RR, Prosperi RF, Luz JHM. Portal vein embolisation in a patient with situs inversus. BMJ Case Rep. 2018;2018:bcr-2017222890. doi:10.1136/bcr-2017-222890

67. Watanabe Y, Osaki A, Waguri N, Terai S. The first case of balloon-occluded retrograde transvenous obliteration and partial splenic embolization for gastric varices in situs inversus abdominus. Clin J Gastroenterol. 2021;14(2):656-661. doi:10.1007/s12328-020-01332-z

68. Gasparrini F, Lenci I, Gagliardi MG, Spada M, Salimei F, Orlacchio A. Repeated TACE in HCC after Fontan surgery and situs viscerum inversus: a case report. Radiol Case Rep. 2021;16(9):2564-2569. doi:10.1016/j.radcr.2021.06.031

69. Eitler K, Mathe Z, Papp V, et al. Double rarity: malignant masquerade biliary stricture in a situs inversus totalis patient. BMC Surg. 2021;21 (1):153. doi:10.1186/s12893-021-01155-w

70. Ninoi T, Nishida N, Kaminou T, et al. Balloon-occluded retrograde transvenous obliteration of gastric varices with gastrorenal shunt: long-term follow-up in 78 patients. AJR Am J Roentgenol. 2005;184(4):1340-1346. doi:10.2214/ajr.184.4.01841340

71. Mönkemüller K, Zimmermann L, Fry LC. Endoscopic examination of the stomach in situs inversus. Clin Gastroenterol Hepatol. 2012;10(4): e33. doi:10.1016/j.cgh.2011.10.031

72. Koyama Y, Kawai T, Matsumoto T, Fukuzawa M, Itoi T. Endoscopic submucosal dissection of early gastric cancer in a patient with situs inversus totalis. VideoGIE. 2020;5(8):347-349. doi:10.1016/j.vgie.2020.04.021

73. Minocha A, Chotiprasidhi P, Elmajian DA. PEG using a preexisting abdominal surgical incision in an obese patient with situs inversus. Gastrointest Endosc. 1999;50(1):128. doi:10.1016/s0016-5107(99)70365-2

74. Sekino Y, Nakajima A, Kubota K. Successful endoscopic papillectomy in a patient with situs inversus. Dig Endosc. 2016;28(5):616. doi:10.1111/den. 12662

75. Galasso D, Ramchandani M, Kalpala R, et al. Successful peroral endoscopic myotomy in situs inversus totalis. Endoscopy. 2014;46(Suppl 1 UCTN):E648-E649. doi:10.1055/s-0034-1390848

76. Choi DH, Park JW, Kim BN, et al. Colonoscopy in situs inversus totalis patients. Am J Gastroenterol. 2008;103(5):1311-1312. doi:10.1111/ j.1572-0241.2007.01782_6.x

77. Téllez-ávila FI, Pattel S, Duarte-Medrano G, Seenath M, Herrera-Mora DR, Lopez-Arce G. A challenging case of giant biliary stones in a patient with situs inversus totalis: conventional ERCP combined with intraductal cholangioscopy and laser lithotripsy. Endoscopy. 2017;49 (10):E248-E249. doi:10.1055/s-0043-115106

78. Inoue T, Yamamoto T, Ishii N, Kobayashi Y, Ito K, Yoneda M. Double-balloon enteroscopy-assisted ERCP in situs inversus with Roux-en-Y hepaticojejunostomy for complex anastomotic stricture dilated with Soehendra stent retriever. Endoscopy. 2017;49(S 01):E46-E47. doi:10.1055/s-0042-121011

79. Kim SB, Kim KH, Kim TN. Successful stone removal by endoscopic retrograde cholangiopancreatography in situs inversus totalis with Billroth-II gastrectomy. Gut Liver. 2015;9(1):118-119. doi:10.5009/gnl14330

80. Tanisaka Y, Ryozawa S, Sudo K, et al. Successful endoscopic retrograde cholangiopancreatography using pancreatic guidewire placement for biliary cannulation in a patient with situs inversus and Billroth-I gastrectomy (with video). JGH Open. 2019;3(6):540-541. doi:10.1002/ jgh3.12163

81. Kumbhari V, Abi-Hanna D, Bassan M. Gastrointestinal: endoscopic ultrasound of a pancreatic lesion in situs inversus. $J$ Gastroenterol Hepatol. 2014;29(2):229. doi:10.1111/jgh.12491

82. Cecinato P, Sassatelli R, Zecchini R, Sereni G, Cavina M, Camellini L. EUS-guided transgastric biliary drainage in complete situs viscerum inversus. Gastrointest Endosc. 2015;81(5):1285-1287. doi:10.1016/j.gie.2014.10.021

83. Togliani T, Pilati S, Mantovani N, et al. Extrahepatic cholangiocarcinoma in a patient with situs inversus totalis diagnosed by endoscopic ultrasound. Endoscopy. 2013;45(Suppl 2 UCTN):E229-E230. doi:10.1055/s-0033-1344327

84. Patel RB, Bhadreshwara K, Hukkeri S. Laparoscopic appendicectomy in a patient with situs inversus totalis. Indian J Surg. 2013;75:41-43. doi:10.1007/s12262-011-0311-9

85. Takeda T, Haraguchi N, Yamaguchi A, et al. Laparoscopic sigmoidectomy in a case of sigmoid colon cancer with situs inversus totalis. Asian $J$ Endosc Surg. 2019;12(1):111-113. doi:10.1111/ases.12483

86. Golash V. Laparoscopic management of acute appendicitis in situs inversus. J Minim Access Surg. 2006;2(4):220-221. doi:10.4103/09729941.28184

87. Palanivelu C, Rangarajan M, John SJ, Senthilkumar R, Madhankumar MV. Laparoscopic appendectomy for appendicitis in uncommon situations: the advantages of a tailored approach. Singapore Med J. 2007;48(8):737-740.

88. Oms LM, Badia JM. Laparoscopic cholecystectomy in situs inversus totalis: the importance of being left-handed. Surg Endosc. 2003;17 (11):1859-1861. doi:10.1007/s00464-003-9051-7

89. Schachter SC, Ransil BJ. Handedness distributions in nine professional groups. Percept Mot Skills. 1996;82(1):51-63. doi:10.2466/ pms.1996.82.1.5

90. Atwez A, Keilani Z. Laparoscopic Roux-en-Y gastric bypass in a patient with situs inversus totalis: case report, technical tips and review of the literature. Int J Surg Case Rep. 2018;45:56-62. doi:10.1016/j.ijscr.2018.03.004

91. Machado NO, Chopra P. Laparoscopic cholecystectomy in a patient with situs inversus totalis: feasibility and technical difficulties. JSLS. 2006;10(3):386-391.

92. Chaouch MA, Jerraya H, Dougaz MW, Nouira R, Dziri C. A systematic review of laparoscopic cholecystectomy in situs inversus. J Invest Surg. 2021;34(3):324-333. doi:10.1080/08941939.2019.1622822 
93. AlKhlaiwy O, AlMuhsin AM, Zakarneh E, Taha MY. Laparoscopic cholecystectomy in situs inversus totalis: case report with review of techniques. Int J Surg Case Rep. 2019;59:208-212. doi:10.1016/j.ijscr.2019.05.050

94. Ahmed Z, Khan SA, Chhabra S, et al. Our experience with surgery in situs inversus: open peptic perforation repair and laparoscopic cholecystectomy in 1 patient and 3 patients respectively. Int J Surg Case Rep. 2016;29:34-38. doi:10.1016/j.ijscr.2016.10.035

95. Salama IA, Abdullah MH, Houseni M. Laparoscopic cholecystectomy in situs inversus totalis: feasibility and review of literature. Int J Surg Case Rep. 2013;4(8):711-715. doi:10.1016/j.ijscr.2013.02.030

96. Al-Jumaily M, Achab M, Hoche F. Laparoscopic cholecystectomy in situs inversus totalis: is it safe? J Laparoendosc Adv Surg Techniq. 2001;11:229-231. doi:10.1089/109264201750539754

97. Krzyzak M, Mulrooney SM. Acute appendicitis review: background, epidemiology, diagnosis, and treatment. Cureus. 2020;12(6):e8562. doi: 10.7759 /cureus. 8562

98. Eng KA, Abadeh A, Ligocki C, et al. Acute appendicitis: a meta-analysis of the diagnostic accuracy of US, CT, and MRI as second-line imaging tests after an initial US. Radiology. 2018;288(3):717-727. doi:10.1148/radiol.2018180318

99. Contini S, Dalla Valle R, Zinicola R. Suspected appendicitis in situs inversus totalis: an indication for a laparoscopic approach. Surg Laparosc Endosc. 1998;8(5):393-394. doi:10.1097/00019509-199810000-00017

100. Almussallam B, Alqahtani SM, Abdo N, et al. Laparoscopic sleeve gastrectomy in a patient with situs inversus totalis and kartagener syndrome. Cureus. 2021;13(8):e17155. doi:10.7759/cureus.17155

101. Bawahab MA. Laparoscopic sleeve gastrectomy in a patient with situs inversus totalis: a case report. J Taibah Univ Med Sci. 2020;15 (4):329-333. doi:10.1016/j.jtumed.2020.04.006

102. Takeno A, Masuzawa T, Katsuyama S, et al. Robotic-assisted proximal gastrectomy using the double-flap technique for early gastric cancer with situs inversus totalis: a case report. Surg Case Rep. 2021;7(1):172. doi:10.1186/s40792-021-01262-z

103. Kigasawa Y, Takeuchi H, Kawakubo H, et al. Laparoscopy-assisted distal gastrectomy in a case of gastric cancer with situs inversus totalis: a case report. Asian J Endosc Surg. 2017;10(1):47-50. doi:10.1111/ases.12326

104. Alhossaini R, Hyung WJ. Robotic assisted distal gastrectomy for gastric cancer in a patient with situs inversus totalis: with video. $J$ Gastrointest Surg. 2017;21(12):2144-2145. doi:10.1007/s11605-017-3576-x

105. Shibata K, Kawamura H, Ichikawa N, et al. Laparoscopic total gastrectomy for advanced gastric cancer in a patient with situs inversus totalis. Asian J Endosc Surg. 2018;11(1):39-42. doi:10.1111/ases.12404

106. Zhu H, Yang K, Hu JK. Gastrectomy for gastric carcinoma with situs inversus totalis: case report and literature review. Hippokratia. 2015;19 (4):360-362

107. Hussan MA, Yang Z, Dong X, Yang H, Li N, Qiao S. A laparoscopic pancreaticoduodenectomy for pancreatic adenocarcinoma in a patient with situs inversus totalis. J Surg Case Rep. 2021;2021(7):rjab316. doi:10.1093/jscr/rjab316

108. Britt J, Jain R, Li R. Robotic radical nephroureterectomy in a patient with situs inversus totalis. Urol Case Rep. 2021;37:101688. doi:10.1016/j. eucr.2021.101688

109. Maurya AP, Kumar S, Gupta V, Chandra A. Management of complicated choledochal cyst in an adult with situs inversus totalis: diagnostic difficulties and technical notes. Indian J Surg. 2017;79(5):464-467. doi:10.1007/s12262-017-1613-3

110. Kudo T, Matsuda T, Urakawa N, et al. Laparoscopic sigmoidectomy with splenic flexure mobilization for colon cancer in situs inversus totalis: preoperative assessment and preparation [published online ahead of print, 2021 Apr 23]. Asian J Endosc Surg. 2021;15:168-171. doi:10.1111/ ases. 12944

111. Kasai S, Hino H, Shiomi A, et al. Robotic-assisted surgery for rectal cancer with situs inversus totalis: a case report. Asian J Endosc Surg. 2021;14(4):803-806. doi:10.1111/ases.12937

112. Benjamens S, van den Berg TAJ, Lange JFM, Pol RA. Living donor hand-assisted laparoscopic nephrectomy in a healthy individual with situs inversus totalis: no need to turn down the donor. BMJ Case Rep. 2020;13(1):e233523. doi:10.1136/bcr-2019-233523

113. Sonawane GB, Moorthy KH, Pillai BS. Complete situs inversus - is it a contraindication for organ donation? Indian J Urol. 2019;35 (4):303-304. doi:10.4103/iju.IJU_82_19

114. Petrović M, Rabrenović V, Stamenković D, et al. Specificities of transplantation of kidneys procured from donors with situs inversus totalis-a case report and review of the literature. Vojnosanit Pregl. 2015;72(1):63-67. doi:10.2298/vsp131010036p

115. van Dellen D, Ready AR, Inston NG. Hand-assisted laparoscopic donor nephrectomy in patients with aberrant inferior vena caval anatomy. Exp Clin Transplant. 2010;8(3):258-261.

116. Ochi A, Unagami K, Akanuma T, et al. Living-donor kidney transplantation in an end-stage renal disease patient with situs inversus totalis: three case reports. IJU Case Rep. 2019;2(2):105-108. doi:10.1002/iju5.12054

117. Reimondez S, Alcaraz Á, Giordano Segade E, Agüero Ramaccioni N, Casarez Díaz G, Maraschio MA. Liver transplant from a donor with situs inversus totalis using orthotopic and retroversus technique: a case report. Transplant Proc. 2019;51(2):585-588. doi:10.1016/j. transproceed.2018.12.002

118. Sun XY, Qin K, Dong JH, et al. Liver transplantation using a graft from a donor with situs inversus totalis: a case report and review of the literature. Case Rep Transplant. 2013;2013:532865. doi:10.1155/2013/532865

119. Raynor SC, Wood RP, Spanta AD, Shaw BW. Liver transplantation in a patient with abdominal situs inversus. Transplantation. 1988;45 (3):661-663. doi:10.1097/00007890-198803000-00034

120. Watson CJ, Rasmussen A, Jamieson NV, et al. Liver transplantation in patients with situs inversus. Br J Surg. 1995;82(2):242-245. doi:10.1002/ bjs. 1800820236

121. Tabrizian P, Joseph TT, Radkani P, Cohen E, Facciuto M. Liver transplantation in an adult recipient with situs inversus totalis: case report and review of the literature. Transplant Proc. 2016;48(9):3163-3166. doi:10.1016/j.transproceed.2016.06.038

122. Na BG, Hwang S, Ahn CS, et al. Deceased donor liver transplantation in an adult recipient with situs inversus totalis: a case report of 10-year clinical sequences following primary and repeat transplantation. Ann Hepatobiliary Pancreat Surg. 2020;24(3):319-325. doi:10.14701/ ahbps.2020.24.3.319

123. Manzia TM, Tariciotti L, Angelico R, Toti L, Anselmo A, Tisone G. Side-to-side caval anastomosis in a patient receiving a liver graft from a marginal donor with situs inversus totalis. Int J Surg Case Rep. 2015;6C:222-225. doi:10.1016/j.jjscr.2014.10.037 
124. Kristek J, Kocík M, Chlupac J, Froněk J. Orthotopic liver transplantation with reduced and rotated graft in adult situs inversus recipient: a case report and a review of reported cases. Ortotopická transplantace jater redukovaným a rotovaným štěpem dospělému př́jemci se situs inversus: kazuistika a přehled publikovaných př́padů. Rozhl Chir. 2018;97(12):568-575.

125. Sankarankutty AK, Cagnolati D, Kemp R, et al. How to do liver transplantation in situs inversus totalis: a simple technique. ANZ J Surg. 2015;85(3):187-188. doi:10.1111/ans.12860

126. Hoyos S, Guzmán C, Correa G, Restrepo JC, Franco H, Cárdenas A. Orthotopic liver transplantation in an adult with situs inversus: an easy way to fit the liver. Ann Hepatol. 2006;5(1):53-55. doi:10.1016/S1665-2681(19)32042-3

127. Kawamoto S, Strong RW, Lynch SV, et al. Liver transplantation in the presence of situs inversus totalis: application of reduced-size graft. Liver Transpl Surg. 1995;1(1):23-25. doi:10.1002/1t.500010106

128. Kim BW, Bae BK, Xu W, Wang HJ, Kim MW. Living donor liver transplantation for an adult patient with situs inversus totalis. World $J$ Gastroenterol. 2010;16(18):2311-2313. doi:10.3748/wjg.v16.i18.2311

129. Ishii T, Fukumitsu K, Ogawa E, Okamoto T, Uemoto S. Living donor liver transplantation in situs inversus totalis with a patient-specific three-dimensional printed liver model. Pediatr Transplant. 2020;24(3):e13675. doi:10.1111/petr.13675

130. Pomposelli JJ, DaCosta MA, McPartland K, Jenkins RL. Retroversus implantation of a liver graft: a novel approach to the deceased donor with situs inversus totalis. Am J Transplant. 2007;7(7):1869-1871. doi:10.1111/j.1600-6143.2007.01843.x

131. Rayhill SC, Scott D, Orloff S, et al. Orthotopic, but reversed implantation of the liver allograft in situs inversus totalis-a simple new approach to a difficult problem. Am J Transplant. 2009;9(7):1602-1606. doi:10.1111/j.1600-6143.2009.02676.x

132. Blum M, Ott T. Animal left-right asymmetry. Curr Biol. 2018;28(7):R301-R304. doi:10.1016/j.cub.2018.02.073

133. Levin M. The embryonic origins of left-right asymmetry. Crit Rev Oral Biol Med. 2004;15(4):197-206. doi:10.1177/154411130401500403

International Journal of General Medicine

Dovepress

\section{Publish your work in this journal}

The International Journal of General Medicine is an international, peer-reviewed open-access journal that focuses on general and internal medicine, pathogenesis, epidemiology, diagnosis, monitoring and treatment protocols. The journal is characterized by the rapid reporting of reviews, original research and clinical studies across all disease areas. The manuscript management system is completely online and includes a very quick and fair peer-review system, which is all easy to use. Visit http://www.dovepress.com/testimonials.php to read real quotes from published authors.

Submit your manuscript here: https://www.dovepress.com/international-journal-of-general-medicine-journal 